\title{
DESENVOLVIMENTO DA FUNÇÃO "STAND BY" APLICADA A EQUIPAMENTOS INDUSTRIAIS AUTOMATIZADOS*
}

\section{Resumo}

Wilker Fernando Matias Lemos ${ }^{1}$ Deiber Luiz Della Torre Camargo² Leandro Cesar Moreno Elbio Auxiliador da Costa ${ }^{4}$

Diferentes equipamentos e processos de produção industrializados utilizam, em maior ou menor grau algum nível de automação e controle, aos quais é possível avaliar através de alguns inputs selecionados (sensores específicos, sequências de operação, temporizadores, memórias, etc.) se o equipamento ou processo encontra-se de fato em plena execução de seu trabalho ou função principal. O objetivo do projeto é "descobrir" o momento em que os equipamentos / processos não estão em operação plena e "automaticamente" modificar o estado de funcionamento de seus órgãos principais e/ou auxiliares como: motores e bombas, qualquer mecanismo de atuação direta, (por meio de redução de velocidade, carga e/ou desligamento controlado e outros) que não precisariam necessariamente estar a pleno funcionamento. O projeto visa à aplicação do funcionamento em modo "stand by" normalmente utilizado em equipamentos eletroeletrônicos a maquinas e processos industriais, possibilitando economia de energia e permitindo que voltem imediatamente à sua condição plena de funcionamento quando maior ritmo operacional for solicitado. $O$ trabalho mostra em aplicações práticas a possibilidade de incluir a filosofia nos sistemas automatizados em diferentes setores da indústria, logo podendo trazer grandes benefícios através de ações estratégicas com baixo custo de implementação.

Palavras-chave: Eficiência Energética, Otimização, Automação, Estratégia.

\section{DEVELOPMENT OF "STAND BY" FUNCTION APPLIED TO AUTOMATED INDUSTRYAL EQUIPMENT}

\begin{abstract}
Different equipment and industrialized production processes use to a greater or lesser degree some level of automation and control, to which it is possible to assess through some inputs selected (specific sensors, operation sequences, timers, memories, etc.) if equipment or process is in fact in full implementation of their job or primary function. The objective of the project is to "discover" the moment that the equipment/processes are not in full operation and "automatically" modify the operating status of its major organs and/or helpers as: motors and pumps, any direct actuation mechanism, (through reduction of speed, cargo and/or controlled shutdown and others) that they wouldn't need necessarily be fully functioning. The project aims at implementing the functioning in "stand by" mode normally used in electrical and electronic equipment for machine tools and industrial processes, allowing energy savings and allowing return immediately to its full operating condition when increased operational tempo is requested. The work shows in practical applications the ability to include automated systems philosophy in different industry sectors, and may soon bring great benefits through strategic actions with low cost of implementation.
\end{abstract}

Keywords: Energy Efficiency, Optimization, Automation Strategy.

1 Engenharia Elétrica, Engenheiro de Automação, Departamento de Produtos Laminados, Villares Metals S/A, Sumaré, SP, Brasil.

2 Engenharia Mecânica, Esp. Gestão Industrial, MBA em Gerenciamento de Manutenção, Gerente de Manutenção, Departamento de Produtos Laminados, Villares Metals S/A, Sumaré, SP, Brasil.

3 Engenharia Controle e Automação, Supervisor de Manutenção, Departamento de Produtos Laminados, Villares Metals S/A, Sumaré, SP, Brasil.

4 Técnico Eletrônico, Técnico de Manutenção, Departamento de Produtos Laminados, Villares Metals S/A, Sumaré, SP, Brasil.

* Contribuição técnica ao $35^{\circ}$ Seminário de Balanços Energéticos Globais e Utilidades e $29^{\circ}$ Encontro de Produtores e Consumidores de Gases Industriais, 13 a 15 de agosto de 2014, São Paulo, SP, Brasil. 


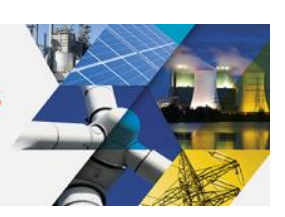

\section{INTRODUÇÃO}

Este trabalho visa demonstrar de forma clara que se pode aplicar um modelo ajustado ao processo buscando garantir uma redução no consumo de energia elétrica, pelo simples fato de colocar seus equipamentos / processos modificando o estado de funcionamento de seus órgãos principais e/ou auxiliares como: motores e bombas, qualquer mecanismo de atuação direta, (por meio de redução de velocidade, carga e/ou desligamento controlado e outros) que não precisariam necessariamente estar a pleno funcionamento.

Diferentes equipamentos e processos de produção industrializados utilizam, em maior ou menor grau algum nível de automação e controle, aos quais é possível avaliar através de alguns inputs selecionados (sensores específicos, sequências de operação, temporizadores e memórias) se o equipamento ou processo encontra-se de fato em plena execução de seu trabalho ou função principal.

\section{MATERIAIS E MÉTODOS}

O estudo das lacunas onde seria aplicado o projeto teve como base os tempos de processo, conhecidos como "Tempo morto", a partir de um software de gerenciamento e armazenamento de dados "ibaAnalyzer", Figura 1, que registra variáveis diversas como: sensores analógicos e digitais, tempo [ms], velocidade $[\mathrm{m} / \mathrm{s}]$, torque $[\mathrm{KN}]$, corrente $[\mathrm{A}]$, materiais diversos, bitola e entre tantas, possibilidade de registro de informação do equipamento e processo.

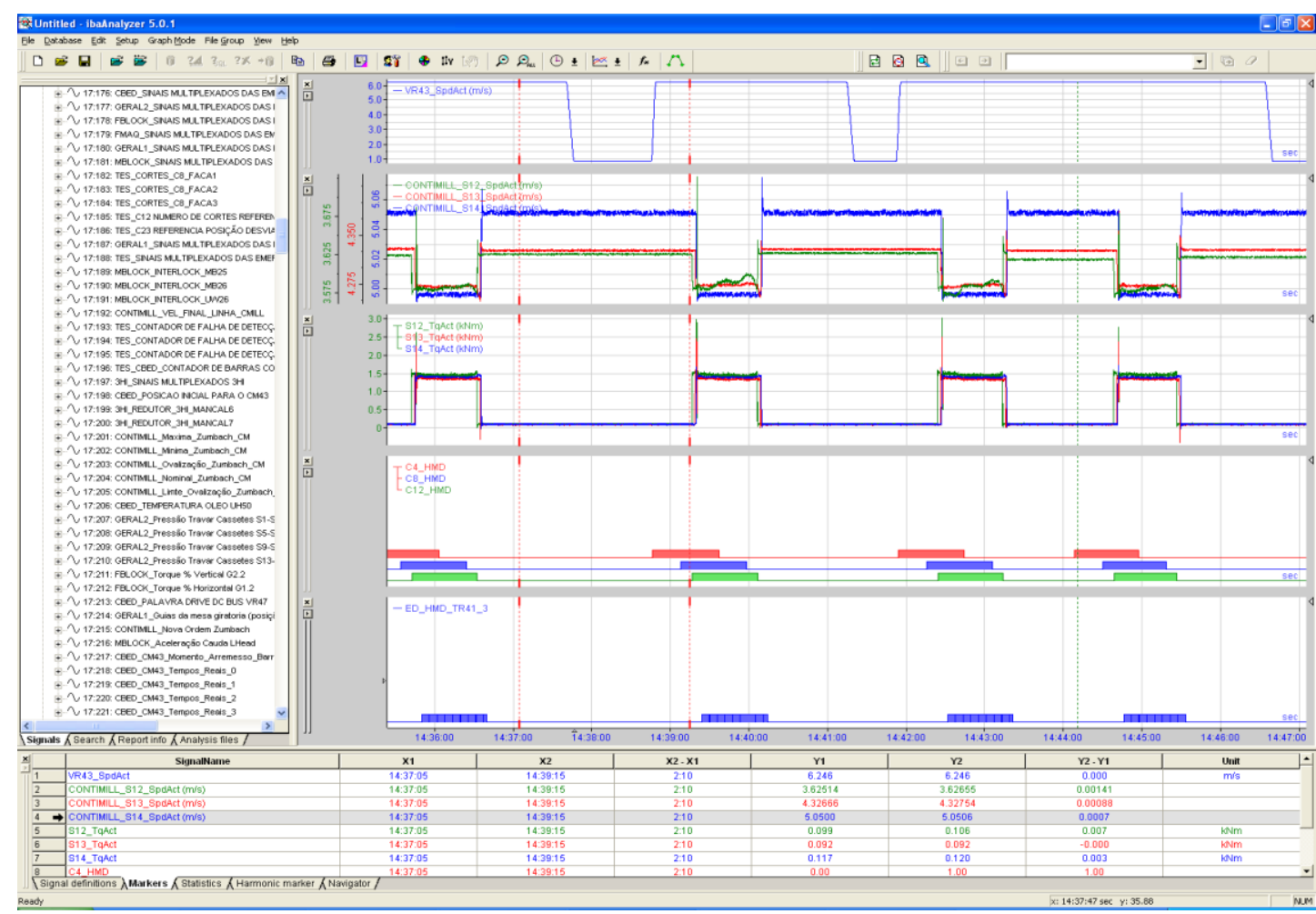

Figura 1 - IbaAnalyzer

* Contribuição técnica ao $35^{\circ}$ Seminário de Balanços Energéticos Globais e Utilidades e $29^{\circ}$ Encontro de Produtores e Consumidores de Gases Industriais, 13 a 15 de agosto de 2014, São Paulo, SP, Brasil. 


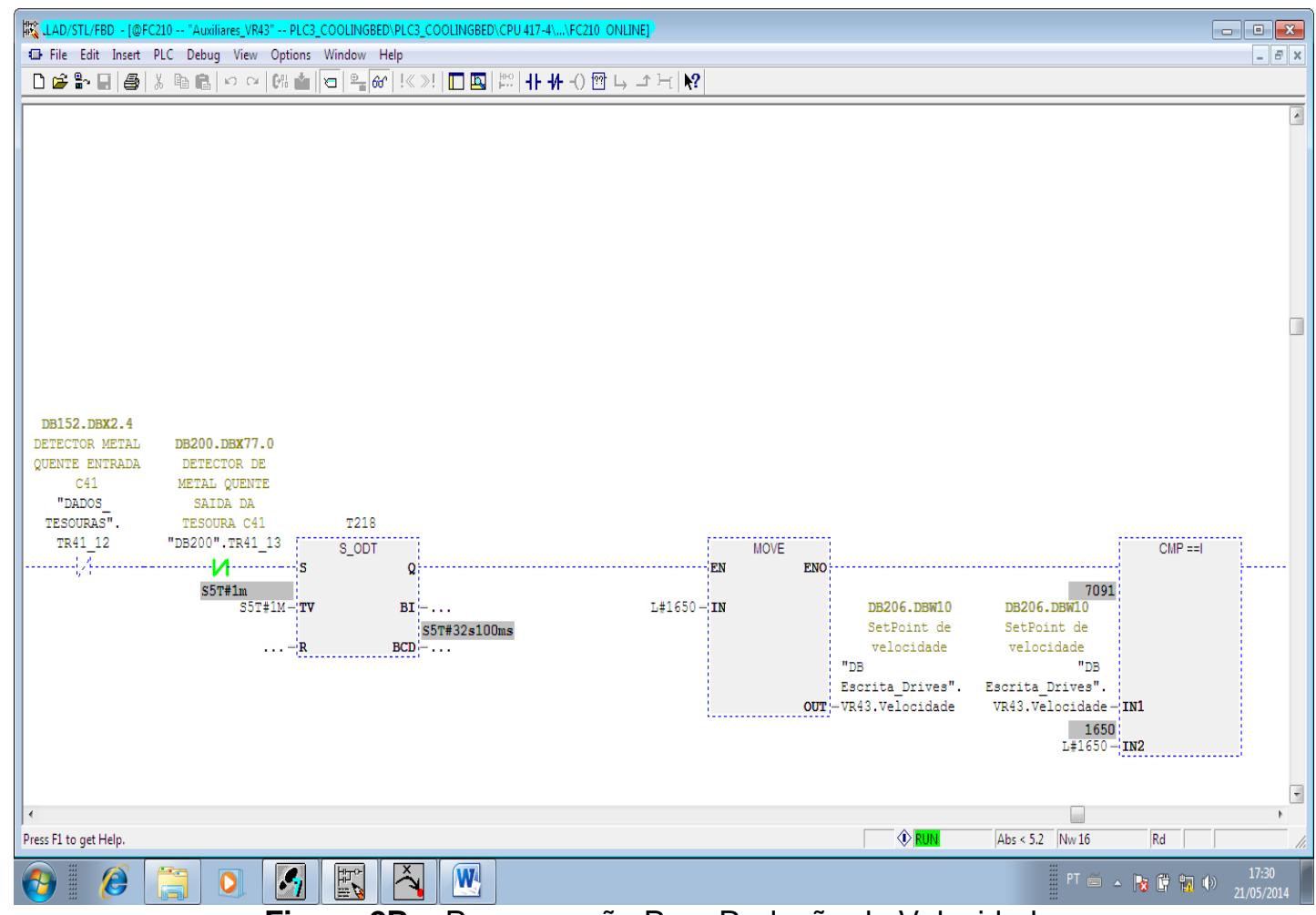

Figura 2B - Programação Para Redução da Velocidade.

Os tempos foram medidos a partir dos dados armazenados no "ibaAnaliyzer", conformo exemplo da Figura 3, abaixo podemos observar que as velocidades são variadas ao longo do tempo, e a somatória do intervalo passam de 2 Horas.

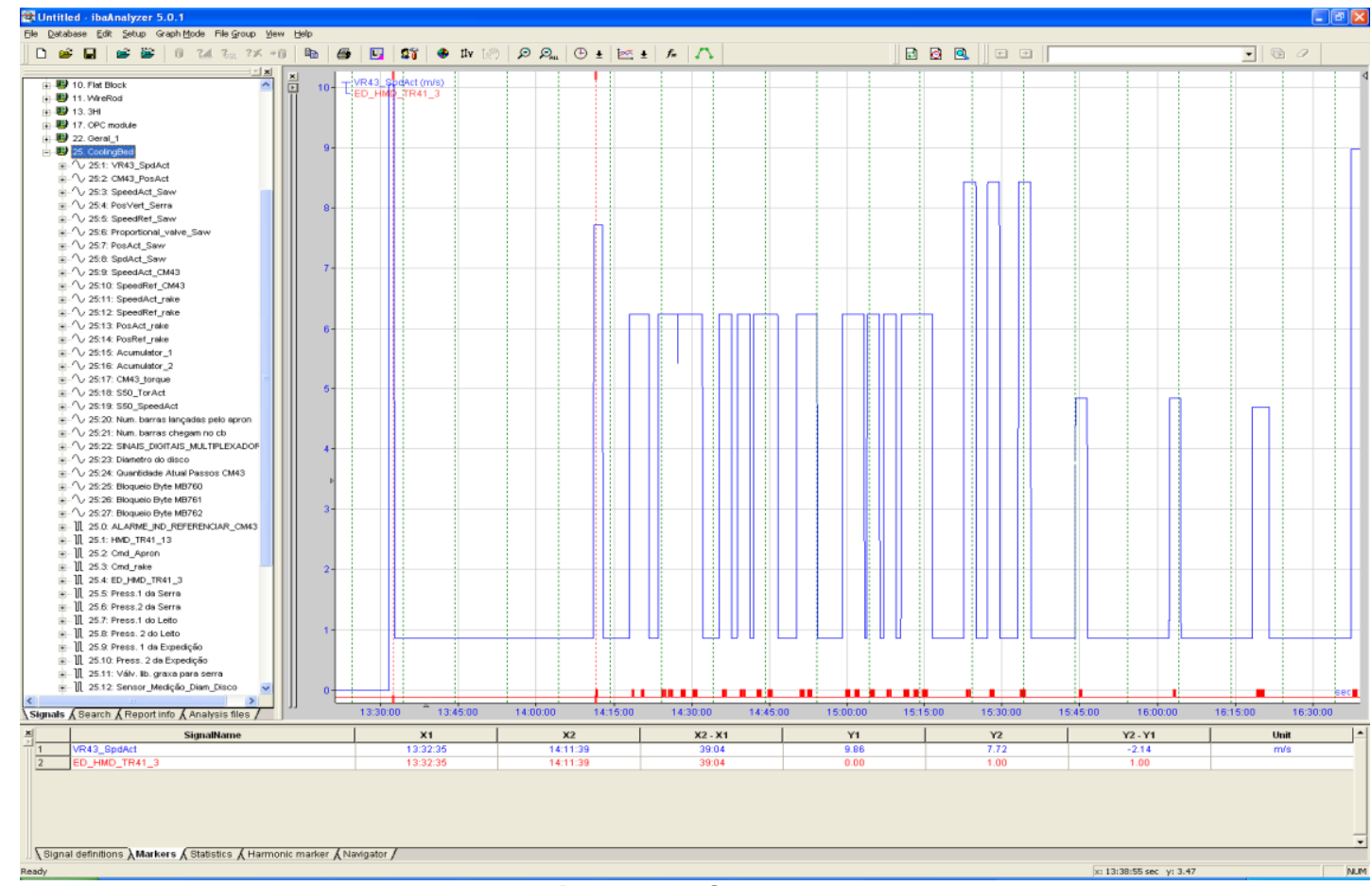

Figura 3 - Coleta de tempos.

Laminador contínuo Multi-Line composto por um conjunto de 16 cadeiras de transformação com múltiplas possibilidades de configuração conforme Figura 4.

* Contribuição técnica ao $35^{\circ}$ Seminário de Balanços Energéticos Globais e Utilidades e $29^{\circ}$ Encontro de Produtores e Consumidores de Gases Industriais, 13 a 15 de agosto de 2014, São Paulo, SP, Brasil. 

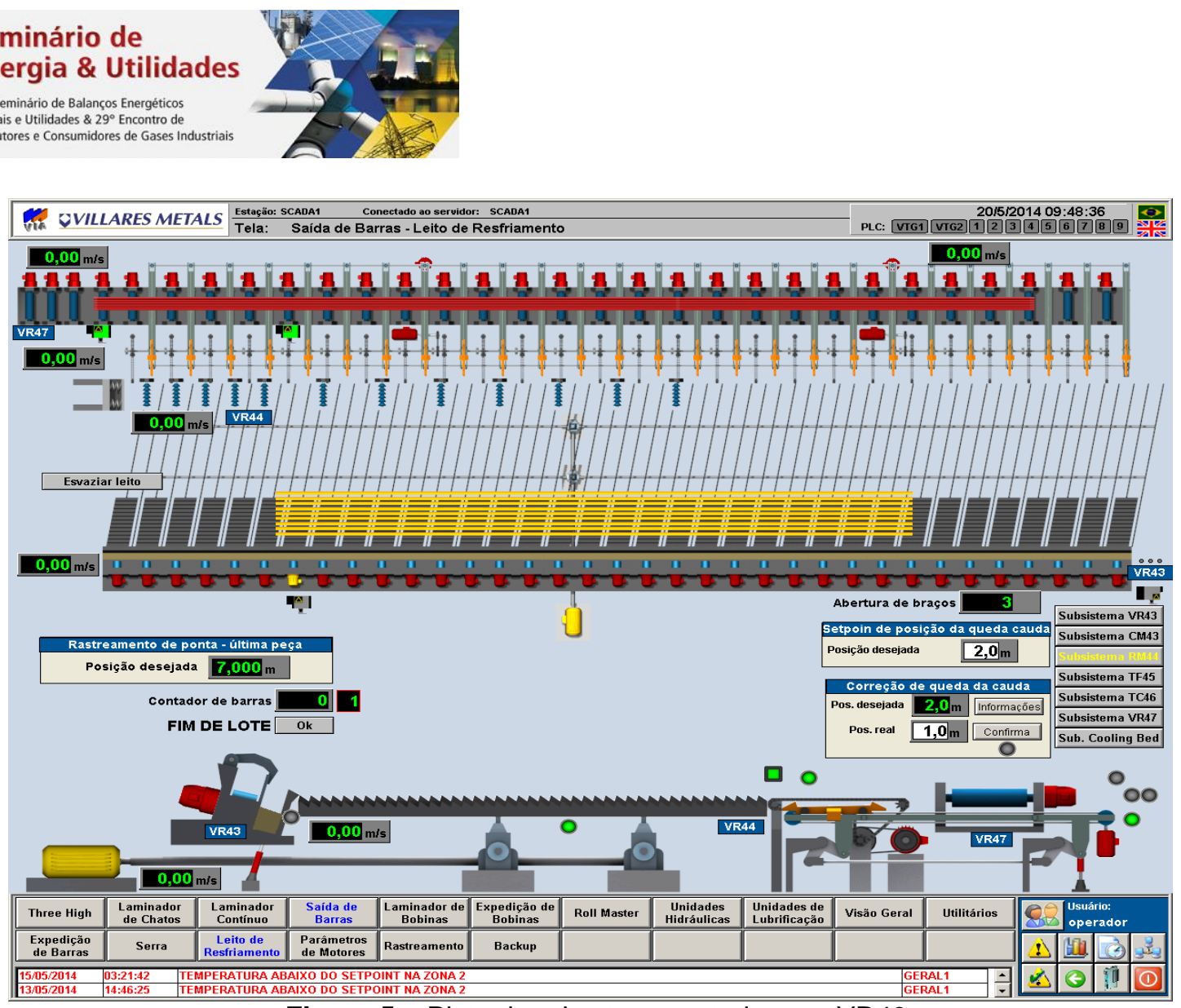

Figura 5 - Pista de rolos transportadores - VR43.

A base utilizada na aplicação do projeto está na análise dos tempos chamado de "tempo morto" dentro do processo. Olhando para todo sistema, percebemos que existem durante as atividades de produção tempos mortos, onde todos os motores do conjunto funcionam sem gerar trabalho, a partir destes dados foram feitos os estudos da aplicação do Projeto.

\section{RESULTADOS E DISCUSSÃO}

Após a implantação do projeto e antes de iniciar a implementação os resultados foram analisados a partir da coleta do consumo da energia elétrica utilizando um software Embrasul Figuras 6 e 7 do conjunto da Pista de rolos transportadora VR43.

* Contribuição técnica ao $35^{\circ}$ Seminário de Balanços Energéticos Globais e Utilidades e $29^{\circ}$ Encontro de Produtores e Consumidores de Gases Industriais, 13 a 15 de agosto de 2014, São Paulo, SP, Brasil. 

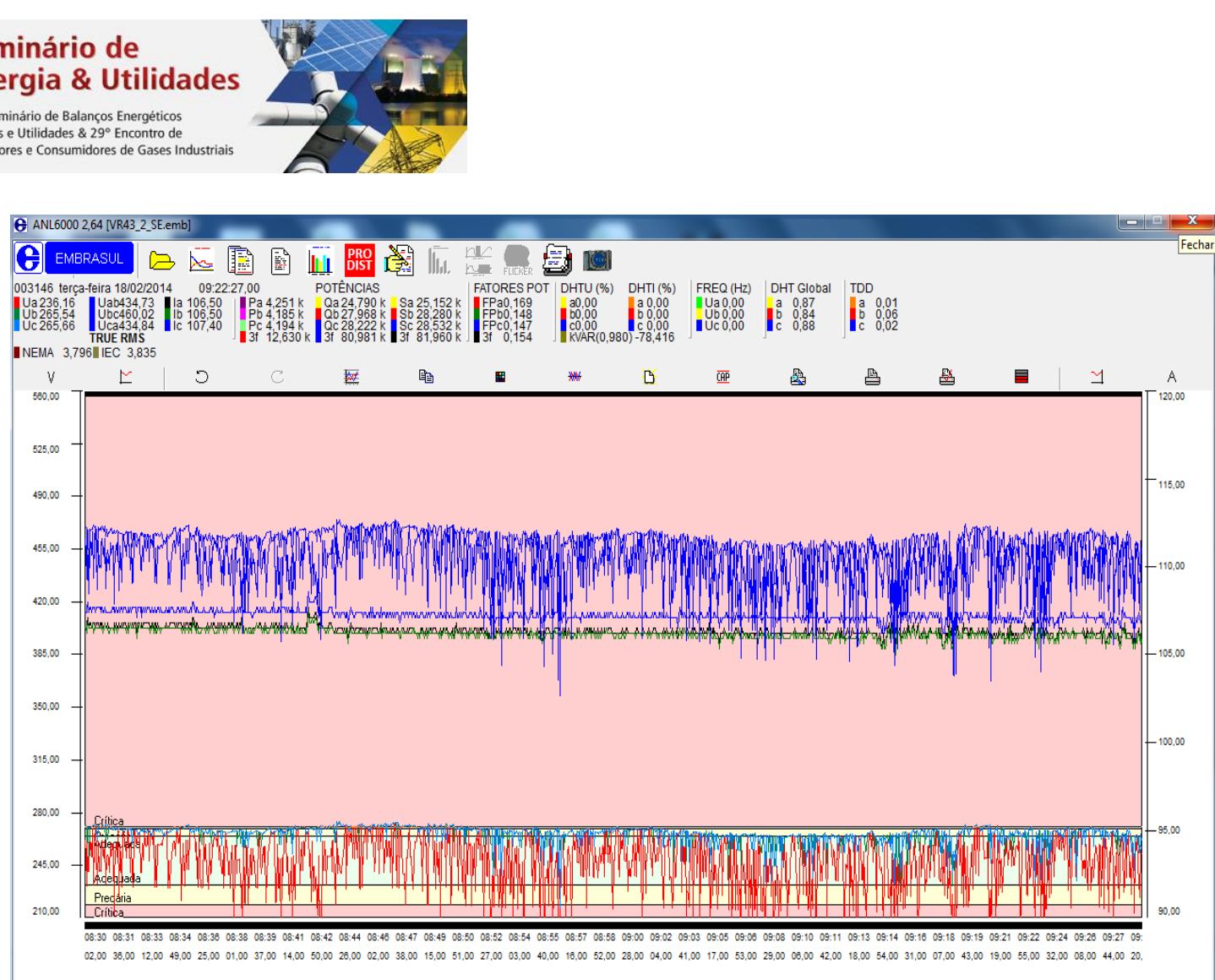

\section{(4) E}

Figura 6 - Coleta de dados antes da implementação do projeto.

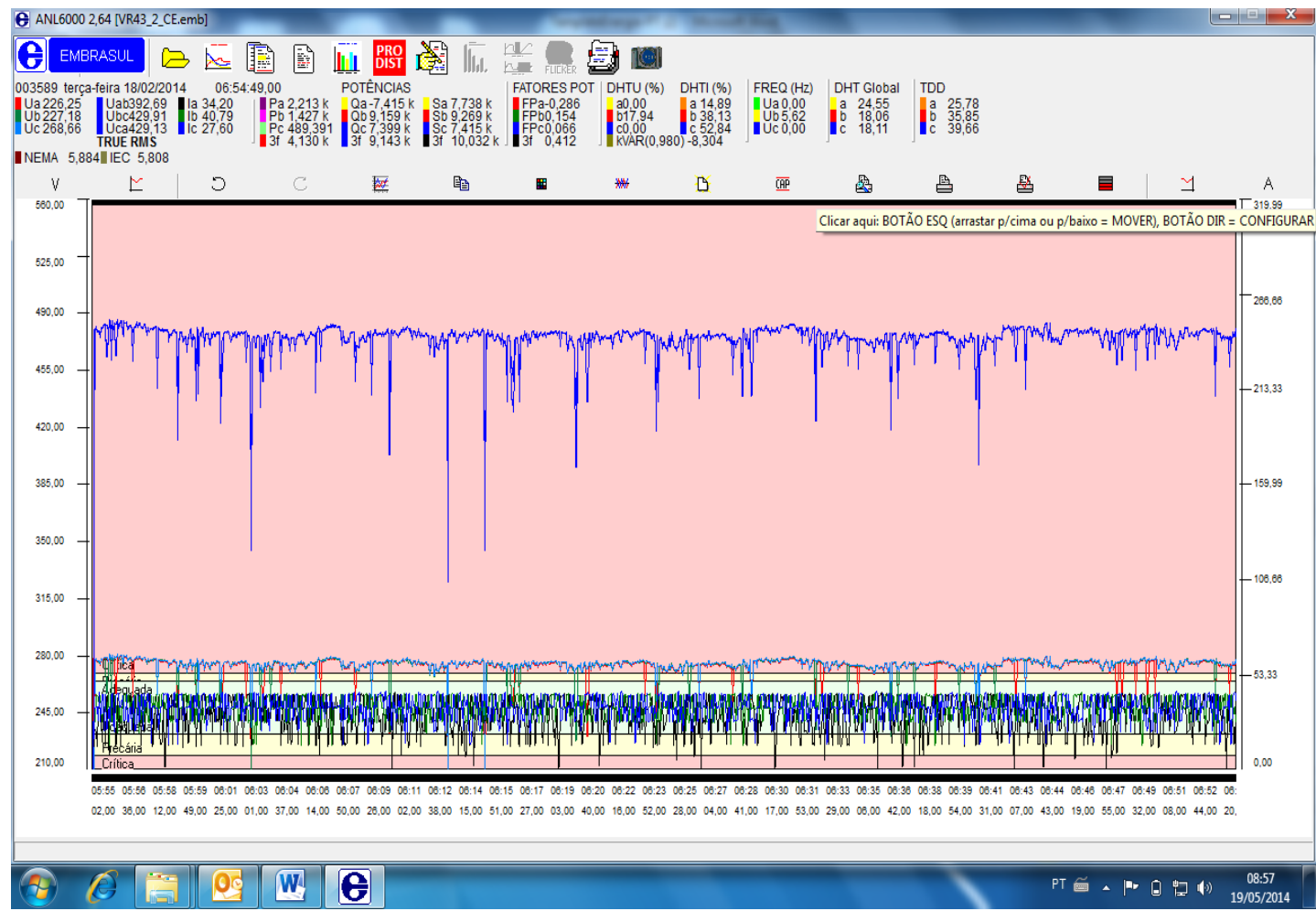

Figura 7 - Coleta de dados após a implementação do projeto.

O relatório com o resultado das medições obtidas pode ser observado na Figura 8 e 9 que foi gerado pelo Software Embrasul, que é uma ferramenta homologada para validar dados de consumo de energia elétrica.

* Contribuição técnica ao $35^{\circ}$ Seminário de Balanços Energéticos Globais e Utilidades e $29^{\circ}$ Encontro de Produtores e Consumidores de Gases Industriais, 13 a 15 de agosto de 2014, São Paulo, SP, Brasil. 


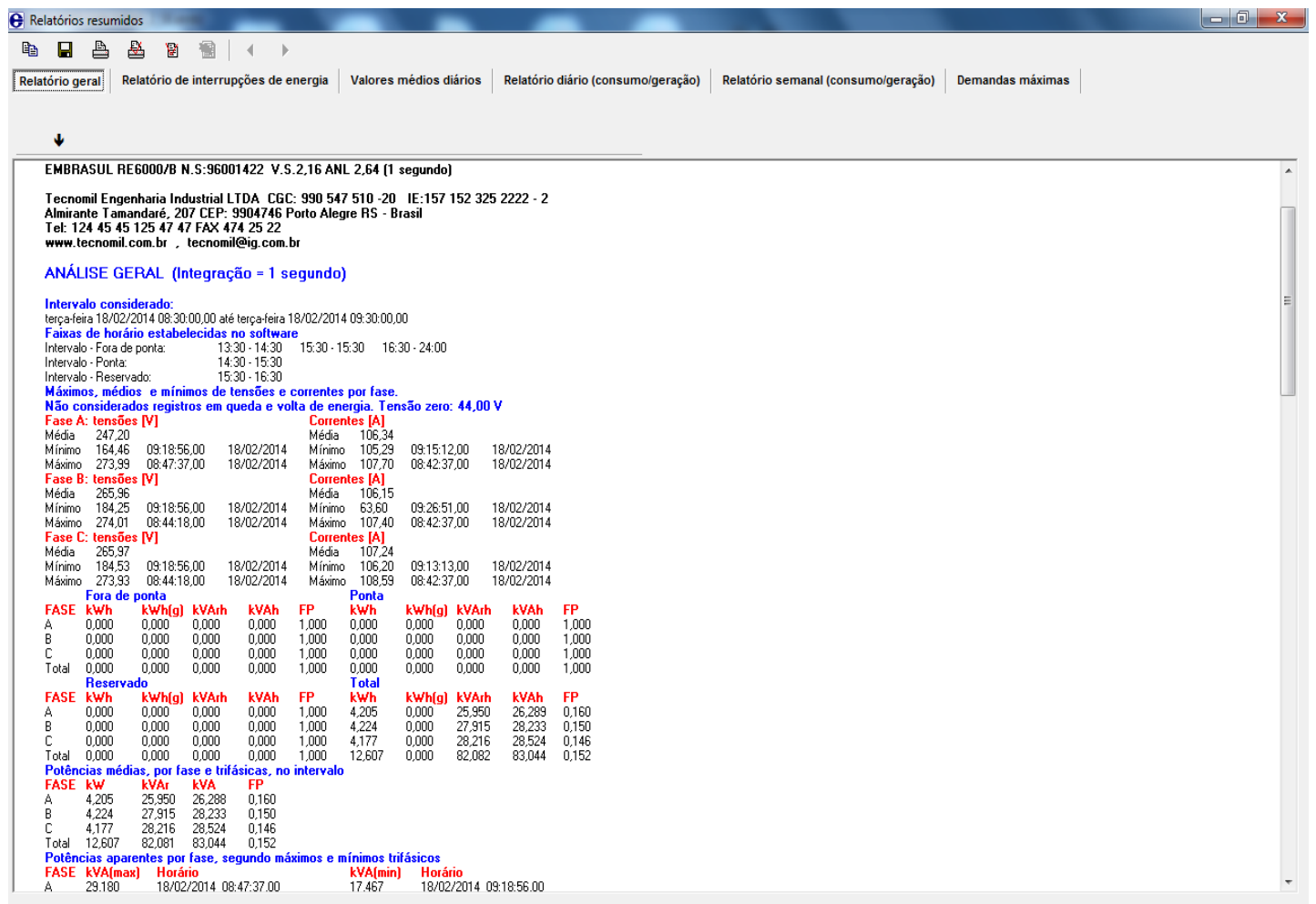

Figura 8 - Relatório da coleta de dados antes da implementação do projeto.

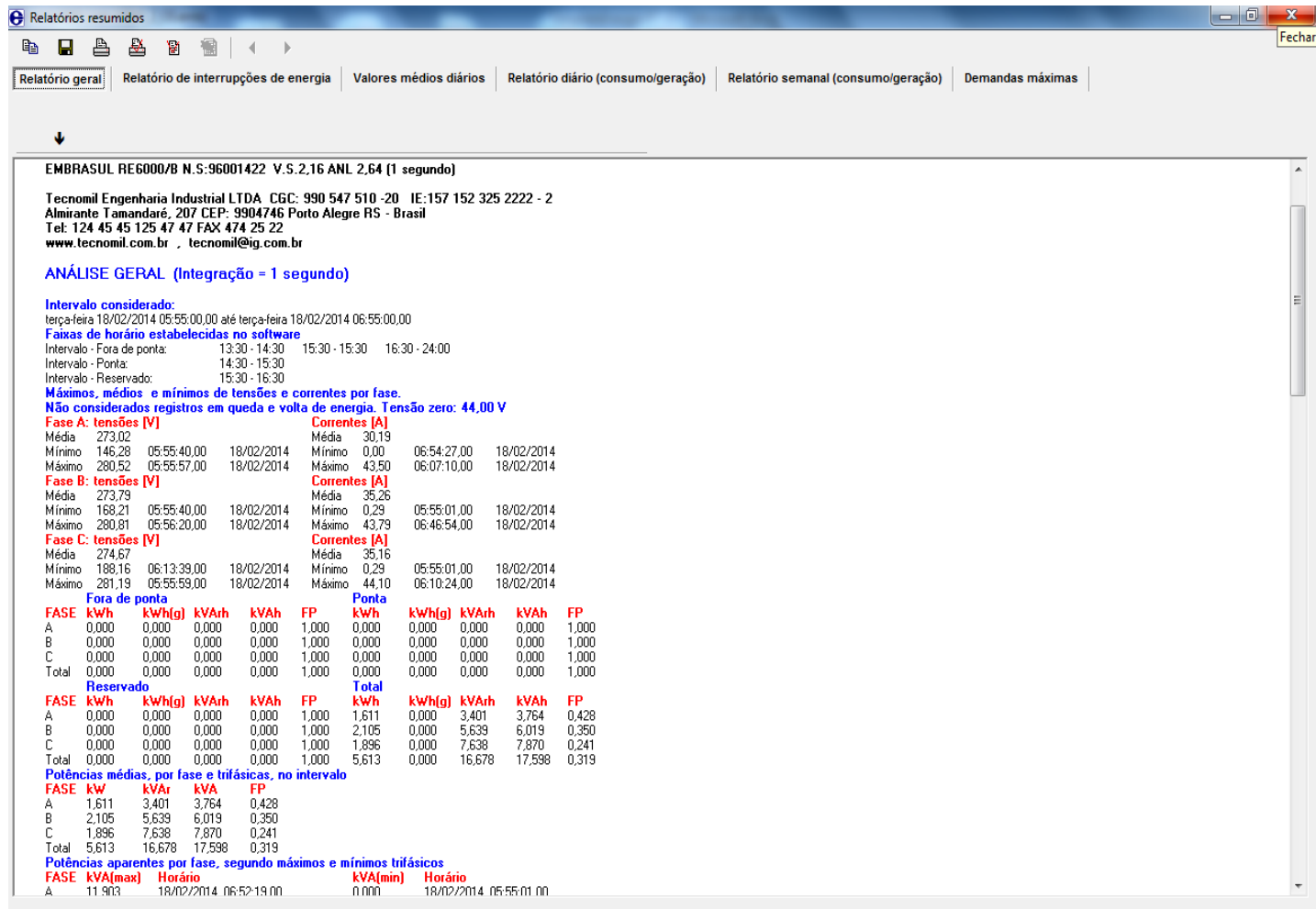

Figura 9 - Relatório da coleta de dados após a implementação do projeto.

O período de coleta dos dados entre o relatório da Figura 8 e 9, tem intervalo de uma hora, e pode ser observado nos mesmos, o resultado obtido é uma economia relacionada à demanda deste projeto, a cada hora que o sistema se manter dentro do tempo morto, tem-se uma economia de $44,5 \%$.

* Contribuição técnica ao $35^{\circ}$ Seminário de Balanços Energéticos Globais e Utilidades e $29^{\circ}$ Encontro de Produtores e Consumidores de Gases Industriais, 13 a 15 de agosto de 2014, São Paulo, SP, Brasil. 


\section{CONCLUSÃo}

A aplicação do funcionamento em modo "stand by" normalmente utilizado em equipamentos eletroeletrônicos a maquinas e processos industriais, se mostrou funcional.

Os resultados ora aqui apresentado demostra que ideias "simples" quando bem implementadas podem resultar em ótima oportunidade de desenvolvimento industrial com economia energética.

Entendemos que este projeto é viável e pode ser expandido para equipamento de maior potência garantindo um retorno representativo.

\section{Agradecimentos}

Aos profissionais da Manutenção Eletrônica da Laminação da Villares Metals S.A. que contribuíram de maneira direta na realização do projeto e principalmente na monitoração dos resultados, em especial ao Engenheiro Eduardo Rogerio de Souza pela dedicação e entrega a este desenvolvimento e a própria Villares Metals S.A. por permitir e estimular este projeto.

\section{BIBLIOGRAFIA}

1 Associação Brasileira de Normas Técnicas. NBR ISO 50001: Sistemas de gestão de energia - Requisitos com orientações para uso. Rio de Janeiro; 2011.

2 International Electrotechnical Commission. IEC 61131-3: Programmable controllers Part 3: Programming languages. Genebra; 2003.

3 Villares Metals S/A. C92000: Manual do Sistema de gestão de energia, norma interna. Sumaré; 2013.

4 Associação Brasileira de Normas Técnicas. NBR 14724: informação e documentação trabalhos acadêmicos - apresentação. Rio de Janeiro; 2005.

* Contribuição técnica ao $35^{\circ}$ Seminário de Balanços Energéticos Globais e Utilidades e $29^{\circ}$ Encontro de Produtores e Consumidores de Gases Industriais, 13 a 15 de agosto de 2014, São Paulo, SP, Brasil. 